\title{
Japanese stimulus package includes billions for computers
}

Tokyo. Many of Japan's universities and government research institutes are likely to receive new computer facilities thanks in part to a political scandal involving charges of tax evasion against Shin Kanemaru, a former top leader of the ruling Liberal Democratic Party (LDP).

Bureaucrats in Japan's science-related ministries and government agencies this week are scrambling to grab a large slice of a $¥ 14,000$ billion (US $\$ 120$ billion) supplementary budget that the government hopes will pull Japan out of recession. Normally, the chief beneficiaries of such one-time supplementary budgets are the Ministry of Construction and construction companies, which receive lucrative public-works projects. But Kanemaru and other LDP politicians under his influence, for example former prime minister Noboru Takeshita, play an important role in directing government money to such public works, and their weakened position has created a unique opportunity to divert money elsewhere.

The Ministry of Education, Science and Culture (MESC) is expected to request about $¥ 1,000$ billion ( $\$ 8.7$ billion), a large portion of which is for supercomputers, local and wide area networks to link computer facilities in universities and university-related institutes and personal computers in elementary schools. Similarly, the Science and Technology Agency (STA) and the Ministry of International Trade and Industry (MITI) together hope to receive several hundred billion yen, much of it for supercomputers and local area networks. These ambitious requests contrast with just over $¥ 100$ billion allocated for science in last year's supplementary budget of $¥ 10,700$ billion (see Nature 360, 8; 1992).

The three government organizations together are asking for about 12 supercomputers and a similar number of minisupercomputers, far more than the three or four supercomputers the government has been buying each year. MITI hopes to replace an old Cray supercomputer at its supercomputer centre in Tsukuba science city and is also requesting a minisupercomputer for its Atom Technology Project (see Nature 362, 279; 1993) and a supercomputer for its Real World Computing project, both of which will be based in the science city. The plan also calls for an upgrade of the local area network that connects computers in the ministry's Tsukuba institutes and for new computer facilities at its regional research institutes elsewhere.

Similarly, STA hopes to improve com- puter facilities at its Institute of Physical and Chemical Research (RIKEN) near Tokyo and at other agency institutes. And MESC has even more ambitious plans to buy a large number of mini-supercomputers and supercomputers for Japan's universities and

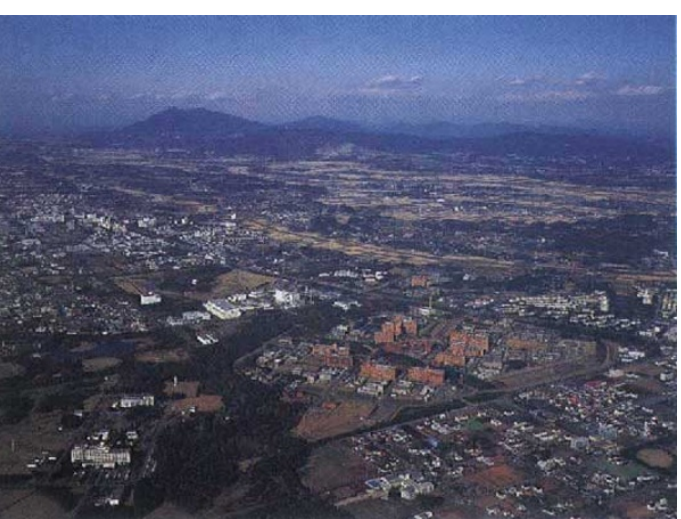

These MITI institutes hope to share the wealth.

to network them together.

When informal negotiations for the supplementary budget began a few weeks ago, MESC, MITI and STA as well as the Ministry of Posts and Telecommunications hoped to request funds for a high-capacity national backbone network to link computer facilities at government research organizations throughout Japan. But each ministry and agency had different ideas about the backbone network, delaying action until fiscal 1994, which begins on 1 April 1994.

Tateo Arimoto, director of STA's science and technology information division, says that such computer network infrastructure has until now been a "low priority" but

that the supplementary budget has provided a "big chance" for change. Although he expects the Ministry of Finance to reduce the requests from the three government organizations, he is confident that the move to improve infrastructure "will continue".

Another factor driving the Japanese government's sudden enthusiasm for high-capacity computer networks is the proposed gigabit national computer network in the United States. Present plans in Japan call for only a six-megabit backbone, considerably less than existing US systems but the most that can be handled by the fibreoptics system of the domestic telecommunications company Nippon Telegraph and Telephone (NTT). The supplementary budget is also expected to contain money to increase the capacity of NTT's fibre-optics network.

Arimoto says that "open bidding" will be held for the new computer systems, and the president of the Japanese subsidiary of the US supercomputer manufacturer Cray Research was reported to have said that he expects Cray to get "about a third" of the supercomputer orders under a 1990 US-Japan agreement on supercomputer trade that calls for fair and open procurement practices. But it is not clear if these rules will apply to the purchase of the many smaller computers.

The supplementary budget is being compiled in time for Japanese Prime Minister Kiichi Miyazawa to discuss parts of it with US President Bill Clinton when he visits Washington in mid-April. Clinton is expected to put pressure on Japan to buy US computers to reduce a large trade imbalance.

David Swinbanks

\section{German education summit planned}

Munich. The long-awaited but often delayed education summit on improving the efficiency of Germany's universities, first proposed a year ago by Chancellor Helmut Kohl (see Nature 358, 361; 1992), will probably take place in September. The impetus for the meeting is the strain of chronic overcrowding, the result of a law that guarantees a place to every student who passes an examination at the end of high school and the fact that students spend too long completing their courses (the average age of a graduate is 28 ).

Delays in fixing a date have in part been caused by disagreements over whether the reforms should in principle be financed by new money. The government has refused to attend a summit where money is on the agenda, insisting that the universities should first put their house in order. It also wants to see more evaluation of research carried out in universities. On the other side, the universities have ruled out preparing for a summit where the possibility of extra financing is excluded.

The presidents of Germany's 16 states last week agreed to negotiate next month with Kohl to break the deadlock. The most likely date is in the autumn; any further delays will land it unhappily in Germany's preelection period.

Alison Abbott 